\title{
The Effect of Seed Extract from Mangifera indica L. on the Growth and Biofilm Formation of Uropathogenic Escherichia coli
}

\author{
Flores-Encarnación, M. ${ }^{1,5}$, Aguilar-Gutiérrez G.R. ${ }^{2}$, Cabrera-Maldonado C. ${ }^{3}$, \\ Valentin-Aguilar I. ${ }^{1,5}$, Xicohtencatl-Cortes J. ${ }^{4}$, Carreño-López R. ${ }^{6}$, García-García S.C. ${ }^{6}$ \\ ${ }^{1}$ Laboratorio de Microbiología Molecular y Celular. Biomedicina, Facultad de Medicina. Benemérita \\ Universidad Autónoma de Puebla. Puebla. Puebla, México. \\ ${ }^{2}$ CISEI. Instituto Nacional de Salud Pública. Cuernavaca, Morelos. México. \\ ${ }^{3}$ Facultad de Ciencias Químicas. Benemérita Universidad Autónoma de Puebla. Puebla. Puebla, México. \\ ${ }^{4}$ Hospital Infantil de México Federico Gómez \\ ${ }^{5}$ Grupo de Académicos de Puebla SC. Puebla. Puebla, México. \\ ${ }^{6}$ Centro de Investigaciones Microbiológicas. Benemérita Universidad Autónoma de Puebla. Puebla. Puebla, \\ México. \\ *Corresponding Author: Flores-Encarnación M, Laboratorio 421 Edif. EMA1. Biomedicina. Facultad \\ de Medicina. Benemérita Universidad Autónoma de Puebla. 13 sur 2702, Col. Volcanes, C.P. 72410. \\ Puebla, Puebla, México.

\begin{abstract}
The extracts of plant origin have shown multiple antibacterial properties. One of the advantages of using plants as an alternative therapeutic is that it has a wide range of antimicrobial activity because it contains a lot of active ingredients that make it toxic to microorganisms. In this study, the effect of M. indica $L$. seed extract on the growth and biofilm formation of uropathogenic E. coli was determinated.
\end{abstract}

Keywords: Mangifera indica, extract, antibacterial, biofilm, E. coli, uropathogenic

\section{INTRODUCTION}

Antibiotic resistance is a current problem that occurs in different countries of the world (Odonkor and Addo, 2011). As is known, acute respiratory infections and diarrheal infections occupy the first places in diseases of infectious origin, however systemic infections are also present among the human population, being difficult to treat due to the multiple cases of resistance to antibiotics (Atiaa et al., 2020). Currently, the search for new substances with antimicrobial activity is frequent by different research groups in the world, especially the study of compounds of natural origin with antimicrobial properties. In this context, various extracts of plant origin have shown multiple antibacterial and antibiofilm properties (Dogruoz et al., 2008). It has been reported that medicinal plants have been used for therapeutic purposes since ancient times (Flores-Encarnación et al., 2016b). One of the advantages of using plants as an alternative therapeutic is that it has a wide range of antimicrobial activity because it contains a lot of active ingredients that make it toxic to microorganisms (Ali et al., 2015; Diao et al., 2013; Flores-Encarnación et al., 2016b; Patra and Baek, 2016). It has been reported that fruit and leaf extracts of some seed plants have shown antibacterial effects against Bacillus subtillis, B. megaterium, Pseudomonas aeruginosa, Staphylococcus aureus, E. epidermidis (Dogruoz et al., 2008). Many examples of colorful fruits are known for their nutritional and antioxidant properties. One of them is Mangifera indica L. (mango), sometimes called "The king of fruits", which is by volume the second largest tropical fruit crop in the world after bananas (Govindan, 2019). M. indica $\mathrm{L}$., is a good source of sugars, vitamins A and C and minerals. The fruit pulp contains vitamins A and C, $\beta$-carotene and xanthophylls (Shibahara et al., 1993). Manzur et al., (2019) reported that the leave extracts of $M$. indica L. reduced the biofilm formation of Staphylococcus spp. in stainless steel. In the present work, the effect of seed extract from M. indica L. on the growth and biofim formation of uropathogenic E. coli was studied. 
The Effect of Seed Extract from Mangifera indica L. on the Growth and Biofilm Formation of Uropathogenic Escherichia coli

\section{MATERIAL AND MethodS}

\subsection{Biological material}

A strain of uropathogenic E. coli CFT073 was used. Bacterial strain was stored in cryovials at $-40^{\circ} \mathrm{C}$ until analysis. The Mangifera indica L. var. Manila fruits used in this study were purchased from a local market of Puebla city, México.

\subsection{Culture conditions}

The trypticase soy broth (BBL Microbiology Systems, Cockeysville, Md) was used for bacterial culture. Test strain that had been cultured at $37^{\circ} \mathrm{C}$ for 24 to 48 hours in trypticase soy broth were seeded crosswise in a Petri dish containing trypticase soy agar, and the plate was incubated at $37^{\circ} \mathrm{C}$ for 24 hours.

\subsection{M. indica seed preparation}

To obtain extracts, 10 seeds from $M$. indica L. were used. The peels were manually removed, while $M$. indica L. pulps by knife were removed. Then seeds were dried using an oven at $60^{\circ} \mathrm{C}$ until it attained constant weight (36 to 96 hours). $M$. indica L. seeds were stored at $0^{\circ} \mathrm{C}$ until analysis. Then, seeds were mechanically fractionated and 5 grams of them was added in $100 \mathrm{~mL}$ of sterile distilled water. To obtain the homogenate, the previous preparation was placed in a $200 \mathrm{~mL}$-glass for blender with stainless steel blades and pulverized during 5 to 10 minutes at $4^{\circ} \mathrm{C}$; immediately the microwaveassisted extraction was performed.

\subsection{Microwave-assisted extraction}

A modified domestic microwave oven was used for the extraction purpose according to the methodology reported by Thakker et al., (2016). The oven has an output power range of $600 \mathrm{~W}$ with a operating frequency of $2500 \mathrm{~Hz}$. The oven was modified by making a hole at the top to accommodate a reflux condenser. To start the extraction, the homogenate of $M$. indica L. seed was placed in a round bottom flask $(250 \mathrm{~mL})$. The flask was then placed in the central position of microwave oven and subsequently subjected to microwave power (according to the conditions mentioned above), applying 10 pulses during 1 minute with break intervals of 1 minute (total extraction time: $20 \mathrm{~min}$ ). After extraction, the resulting extracts were filtered using compressed sterile cotton gauges to remove large plant debris and then filtered with filter paper. After filtration, the samples were aliquoted and kept at $-5^{\circ} \mathrm{C}$ until use.

\subsection{Antibacterial activity}

Antibacterial activity of $M$. indica seed extract was determined using technique of well diffusion in agar. Briefly, tripticasein soy agar plates containing $20 \mathrm{~mL}$ and $40 \mathrm{~mL}$ of medium were prepared. Sterile Petri dishes $(150 \mathrm{~mm})$ were used. Plates were inoculated by crossstriation with uropathogenic E. coli. Each inoculum contained approximately $10^{6} \mathrm{CFU} \mathrm{mL}^{-1}$. Subsequently, 5 wells were made on the tripticasein soy agar plate with the aid of the mouthpiece of a sterile glass Pasteur pipette. Then, different volumes of $M$. indica seed extract ( 5 to $750 \mu \mathrm{L}$ ) were added in each well. The agar plates were allowed to stand for about $20 \mathrm{~min}$ at room temperatura and then they were incubated at $37^{\circ} \mathrm{C}$ for $24 \mathrm{~h}$. The halo diameter of bacterial growth inhibition was measured using a caliper ruler. The analyses were conducted in triplicate.

\subsection{Detection of biofilm}

For biofilm detection of uropathogenic E. coli, the calcofluor white staining was used according to modified methodology described by Ramos et al., (2006) and Flores-Encarnación et al., (2016a). Briefly, Luria Bertani agar plates containing $0.02 \%$ calcofluor White and the technique of well diffusion in agar were used. So, $20 \mu \mathrm{L}$ of uropathogenic E. coli incubated overnight was inoculated by crossstriation. Subsequently, 4 wells were made on agar with the aid of the mouthpiece of a sterile glass Pasteur pipette. Then, two volumes of $M$. indica seed extract were added in each well: 200 and $750 \mu \mathrm{L}$. The agar plates were incubated at $37^{\circ} \mathrm{C}$ during $48-72 \mathrm{~h}$ into a chamber to keep moisture. Then, Luria Bertani agar plates containing $0.02 \%$ calcofluor White were exposed to UV light and the fluorescence emitted by exopolysaccharides of cells forming biofilm was observed. Assays on all samples were repeated in duplicate. 
The Effect of Seed Extract from Mangifera indica L. on the Growth and Biofilm Formation of Uropathogenic Escherichia coli

\section{RESULTS}

As described above, the effect of $M$. indica seed extract on the growth and biofim formation of uropathogenic E. coli was determined. For this, the mango seeds were pulverized and extracted by a microwave-assisted method as indicated in Materials and Methods. Antibacterial activity of extract was determined using technique of well diffusion in agar using tripticasein soy agar plates containing $20 \mathrm{~mL}$ and $40 \mathrm{~mL}$ of medium. Plates were inoculated with uropathogenic E. coli and 5 wells were made on the tripticasein soy agar. Then, different volumes of $M$. indica seed extract were added in each well: 5 to $750 \mu \mathrm{L}$ and the agar plates were incubated at $37^{\circ} \mathrm{C}$ for $24 \mathrm{~h}$. The results obtained are shown in Fig. 1. As shown in Fig. 1A, uropathogenic E. coli was grown in trypticase soy agar at $37^{\circ} \mathrm{C}$ for $24 \mathrm{~h}$ in the presence of $500 \mu \mathrm{L}$ of $M$. indica seed extract, which was added in one quadrant of the surface of trypticase soy agar. As can be seen in the figure, uropathogenic E. coli had a good growth on trypticasein soy agar, except in the area where the $M$. indica seed extract was placed. This indicated that the seed extract obtained had antibacterial properties. Next, some tests were performed using the agar diffusion technique. For this, some paper discs were impregnated with 1 to $10 \mu \mathrm{L}$ of $M$. indica seed extract. At these low amounts of the extract, effect was not observed on the growth of uropathogenic E. coli (data not shown). Due this, the well diffusion tests were used. Thus, different amounts of $M$. indica seed extract were placed in each well. Fig. 1B shows the results obtained when $5,10,20,30$ and $50 \mu \mathrm{L}$ of $M$. indica seed extract were placed in wells. As shown in Fig. 1B, the $M$. indica seed extracts did not inhibit the growth of uropathogenic E. coli. Similar results were observed using $75,100,125$ and $150 \mu \mathrm{L}$ of $M$. indica seed extract (Fig. 1C). Using larger amounts of the $M$. indica seed extract such as $400,500,600,700$ and $750 \mu \mathrm{L}$, the growth inhibition of $E$. coli was observed. The results obtained are shown in Fig. 1D. As shown in this figure, the M. indica seed extracts produced the growth inhibition halo. In most cases, the halo came to measure around 18 to 25 $\mathrm{mm}$ in diameter. Due to these results, it was proposed that the $M$. indica seed extracts did not diffuse in the best way due to agar thickness. As mentioned in Materials and Methods, the trypticasein soy agar plates containing $40 \mathrm{~mL}$ of medium were used.

On the other hand, the effect of $M$. indica L. seed extract on biofilm formation of uropathogenic $E$. coli was determined. For that, Luria Bertani agar plates containing $0.02 \%$ calcofluor White were used as described in Materials and Methods. The results obtained are shown in Fig. 2. As seen in Fig. 2A, the production of expolysaccharides in biofilm was inhibited by presence of $M$. indica seed extract. The fluorescence emitted by calcofluor White was only observed surrounded all wells containing the $M$. indica extracts (outside of bacterial growth inhibition halos). This suggested that there was no presence of exopolysaccharides in the growth inhibition area of uropathogenic E. coli. Outside the growth inhibition halos, the fluorescence due to calcofluor white was observed, indicating that uropathogenic E. coli produced exopolysaccharides on the agar surface in the absence of $M$. indica seed extract. As a reference, uropathogenic E. coli was cultived cross-streaked in a Luria Bertani agar plate containing $0.02 \%$ calcofluor White in absence of $M$. indica seed extract. The production of exopolysaccharides was observed (Fig. 2B).

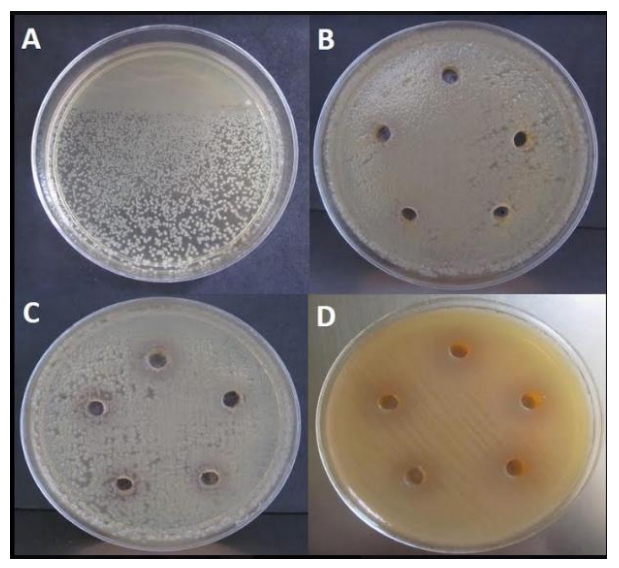

Fig1. The effect of M. indica L. seed extract on the growth of uropathogenic E. coli. A. Antibacterial activity of an extract aliquot. B. 5 to $50 \mu \mathrm{L}$ of extract were added to wells. C. 50 to $150 \mu \mathrm{L}$ of extract were added to wells. D. 400 to $750 \mu \mathrm{L}$ of extract were added to wells. In all cases, extracts were placed in increasing concentrations in the counterclockwise direction, starting with the top well. 
The Effect of Seed Extract from Mangifera indica L. on the Growth and Biofilm Formation of Uropathogenic Escherichia coli

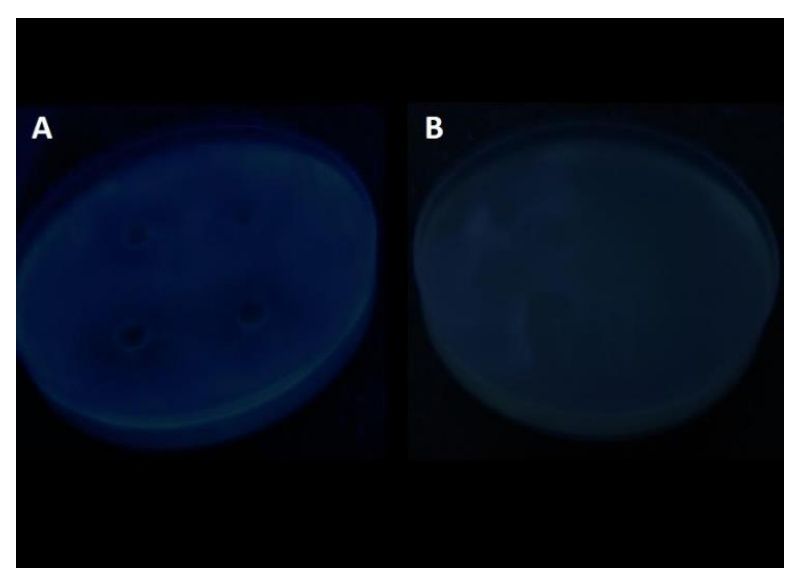

Fig2. The effect of $M$. indica L. seed extract on biofilm formation of uropathogenic E. coli. A. Inhibition of production of biofilm (expolysaccharides) in Luria Bertani agar plate containing $0.02 \%$ calcofluor White. B. Control condition.

\section{DISCUSSION}

Resistance to antibiotics by bacteria is a growing problem. As a result, the treatment of many infectious diseases is difficult and expensive (Odonkor and Addo, 2011). At present, various products of plant origin are known to possess antimicrobial properties. Attacking not only bacteria, but also viruses, fungi and even parasites (Abubakar, 2009; Akinpelu and Onakoya, 2006; Castaño et al., 2010; Dogruoz et al., 2008). One of the advantages of using plants as an alternative therapeutic is that it has a wide range of antimicrobial activity because it contains a lot of active ingredients that make it toxic to microorganisms (Flores-Encarnación et al., 2016b). In them, a mixture of aldehydes, alcohols, terpenoids and other compounds have been found (Diao et al., 2013; Flores-Encarnación et al., $2016 b$ ). The plant products have found also wide application as alternatives to conventional therapy and food preservation (Carhuapoma et al., 2009; Castaño et al., 2010; Dogruoz et al., 2008; Patra and Baek, 2016; Rincón-Mejía et al., 2012). Among those plant products, extracts of M. indica L. obtained from the leaves have shown antibacterial properties. $M$. indica L, commonly called as mango, is a plant belonging to the family Anacardiaeceae; it is one of the most popular tropical fruit trees in the world (Akinpelu and Onakoya, 2006; Kabuki et al., 2000). In the present study, the effect of seed extract from $M$. indica $\mathrm{L}$. on the growth and biofilm formation of uropathogenic E. coli was studied. The results obtained shown that the presence of $M$. indica seed extract inhibited the growth of uropathogenic E. coli, indicating that the seed extract obtained had antibacterial properties (Fig. 1A). This was confirmed using the well diffusion technique in agar plates, where it was observed that using 400 to $750 \mu \mathrm{L}$ of the $M$. indica seed extract the growth inhibition of E. coli was observed (Fig. 1D). As it was shown in this figure, all samples of $M$. indica seed extracts produced the growth inhibition halo around 18 to $25 \mathrm{~mm}$ in diameter, probably because the seed extracts did not diffuse in the best way due to agar thickness. At amounts lower than $400 \mu \mathrm{L}$ of the $M$. indica seed extract, no effect was observed on the growth of uropathogenic E. coli. As other authors have reported, M. indica L. seed kernel extract showed its inhibitory effect against coliform and $E$. coli isolates and it has been used in food products or cosmetics due to its bacteriostatic and antibacterial properties and antifungal and antioxidant activities (Abdalla et al., 2007; Hannan et al., 2013). It has been reported that M. indica L. plant has also several biological properties as like to treat mouth infections in children, diarrhea, dysentery, gastrointestinal tract disorders, typhoid fever, sore throat and scurvy. It has been reported the antibacterial efficacy of stem bark extracts of $M$. indica against some bacteria associated with respiratory tract infections (Abubakar, 2009; Hannan et al., 2013). M. indica L. is indigenous to eastern Asia, Myanmar (Burma), and Assam state of India. Cultivated in many tropical regions, $M$. indica L. has special significance in Africa, and a large part of Asia including Pakistan, India, Bangladesh and Philippines and other regions in the world (Abubakar, 2009). In the present study, the extracts were obtained from $M$. indica seeds, which is relevant because most people, at least in Mexico, consider this material as waste and throw it away. However, as could be seen, $M$. indica seeds have broad biotechnological potential as a source of antimicrobial substances. It has been reported that the $M$. indica seed represents $10 \%$ to $25 \%$ of the entire fruit weight, depending on the mango variety. Studies have shown that $M$. indica seed kernel can be a rich source of different 
phenolic and antioxidant compounds (Abdalla et al. 2007; Dorta et al. 2013; Maisuthisakul and Gordon, 2009). Lim et al., (2019) reported that gallic acid, caffeic acid, rutin and penta-O-galloyl-bD-glucose were identified to be present in $M$. indica seed kernel. On the other hand, in this study the effect of $M$. indica $L$. seed extract on biofilm formation of uropathogenic $E$. coli was determined. The results obtained shown that the production of expolysaccharides in biofilm of uropathogenic $E$. coli was inhibited by presence of $M$. indica seed extract. The fluorescence emitted by calcofluor White was only observed surrounded all wells containing the $M$. indica extracts (there was no presence of exopolysaccharides in the growth inhibition area of uropathogenic E. coli) (Fig. 2). The presence of biofilm gives certain advantages to bacteria as protection from the environment, resistance to the bactericidal action of the antimicrobials, altered host defense mechanisms (hinders macrophage phagocytic activity by interfering with the coating antibodies to block opsonization and phagocytosis) (Flores-Encarnación et al., 2014; Kostakioti et al.,, 2013; Shiau and Wu, 1998). The results obtained in this study are in agreement with that reported by other authors. Adesina et al., (2015) reported that M. indica, Psidium guajava and Ocimum gratissimum leaf extracts prevented the E. coli biofilm formation on catheters. Manzur et al., (2019) reported that extract of $M$. indica L. leaves reduced biofilms of Staphylococcus spp. Finally, it is important to mention that the microwave-assisted extraction method allowed obtaining the $M$. indica seed extracts with a good antibacterial activity and reduced the extraction time to 20 min under the conditions tested. Major conventional techniques being employed like Soxhlet extraction, heating-stirring method, heat-refluxing, consume large quantity of solvents and require longer extraction time. Compared to traditional techniques, microwave-assisted extraction is characterized by reduced solvent consumption, shorter extraction time, and increased pollution prevention (Cui et al., 2015; Cvjetko Bubalo et al., 2016; Pal and Jadeja, 2020).

\section{CONCLUSION}

At present, the search for new substances with antibacterial activity is carried out in different parts of world, with plant extracts being an option for the extraction of their active ingredients. In this study, the extracts of the $M$. indica $\mathrm{L}$. seed showed antibacterial and antibiofilm activities. It is important to carry out more studies to know about the possible mechanisms of its antimicrobial action.

\section{ACKNOWLEDGEMENT}

We appreciate the enthusiastic collaboration and technical support of IB. Melchor-Jiménez N. and MC. Nava-Nolazco R.M. Thank to Facultad de Medicina-BUAP and Grupo de Académicos de Puebla $\mathrm{SC}$ for the facilities provided for the development of this work.

\section{REFERENCES}

[1] Abdalla A.E.M., Darwish S.M., Ayad E.H.E. and El-Hamahmy R.M. (2007). Egyptian mango by product 2: antioxidant and antimicrobial activities of extracts and oil from mango seed kernel. Food Chem. 103:11411152 .

[2] Abubakar E.M.M. (2009). Antibacterial efficacy of stem bark extracts of Mangifera indica against some bacteria associated with respiratory tract infections. Scientific Res. Essay. 4:1031-1037.

[3] Adesina T.D., Nwinyi O.C. and Olugbuyiro J.A.O. (2015). Prevention of bacterial biofilms formation on urinary catheter by selected plant extracts. Pak J Biol Sci. 18:67-73.

[4] Akinpelu D.A. and Onakoya T.M. (2006). Antimicrobial activities of medicinal plants used in folklore remedies in south-western. Afr. J. Biotechnol. 5:1078-1081.

[5] Ali B., Al-Wabel N.A. Shams S., Ahamad A., Khan S.A. and Anwar F. (2015). Essential oils used in aromatherapy: a systemic review. Asian Pac. J. Trop. Biomed. 5:601-611.

[6] Atiaa A., Elyounsib N., Abiredc A., Wanisd A., Ashoura A. (2020). Antibiotic resistance pattern of bacteria isolated from patients with upper respiratory tract infections; a four-year study in Tripoli city. Iberoamer. J. Med. 3:155-160.

[7] Carhuapoma M.Y., López S.G., Roque M.A., Velapatiño B., Bell C.C. and Whu D.W. (2009). Actividad antibacteriana del aceite esencial de Minthostachys mollis Griseb "RUYAQ MUÑA". Ciencia e investigación. 12:83-89. 
The Effect of Seed Extract from Mangifera indica L. on the Growth and Biofilm Formation of Uropathogenic Escherichia coli

[8] Castaño H.I.P., Ciro G.G., Zapata J.E.M. and Jiménez S.L.R. (2010). Actividad bactericida del extracto etanólico y del aceite esencial de hojas de Rosmarinus officinalis L. sobre algunas bacterias de interés alimentario. VITAE Rev. Fac. Quim. Farmac. 17:149-154.

[9] Cui Q., Peng X., Yao X.H., Wei Z.F., Luo M., Wang W., Zhao C.J., Fu Y.J. and Zu Y.G. (2015). Deep eutectic solvent-based microwave-assisted extraction of genistin, genistein and apigenin from pigeon pea roots. Separation and Purif. Technol. 150: 63-72.

[10] Cvjetko Bubalo M., Curko N., Tomasevic M., Ganic K.K. and Redovnikovic I.R. (2016). Green extraction of grape skin phenolics by using deep eutectic solvents. Food Chem. 200:159-166.

[11]Diao W.R., Hu Q.P., Feng S.S., Li W.Q. and Xu J.G (2013). Chemical composition and antibacterial activity of the essential oil from green huajiao (Zanthoxylum schinifolium) against selected foodborne pathogens. J. Agric. Food Chem. 3:6044-6049.

[12] Dogruoz N., Zeybek Z. and Karagoz A. (2008). Antibacterial activity of some plant extracts. IUFS J. Biol. 67:9-16.

[13] Dorta E., Lobo M.G. and Gonzalez M. (2012). Reutilization of mango byproducts: study of the effect of extraction solvent and temperature on their antioxidant properties. J. Food Sci. 71:80-88.

[14] Flores-Encarnación M., Aguilar-Gutiérrez G.R., Ixtepan-Tejero C., Juárez-Salazar G., Martínez-Vaquero J.L., Cabrera-Maldonado C. and Xicohténcatl-Palacios R.C. (2014). Biofilm: a natural mechanism of bacterial resistance. Int. J. Curr. Res. 6. 10420-10424.

[15] Flores-Encarnación M., Guzmán-Flores J.E., Amador-Bravo D., Aguilar-Gutiérrez, G.R. and CabreraMaldonado C. (2016a). An assay for detection of uropathogenic Escherichia coli biofilm using calcofluor. Inter. J. Res. Studies Biosc. 4:40-45.

[16] Flores-Encarnación M., Nava-Nolazco R.M., Carreño-López R., Aguilar-Gutiérrez G.R., García-García S.C. and Cabrera-Maldonado C. (2016b). The antibacterial effect of plant-based essential oils. Inter. J. Res. Stud. Biosci. 4:1-6.

[17] Govindan V. (2019). Mango (Mangifera indica L.), plant produces an exotic fruits on stem. Inter. J. New Innovat. Engin. Technol. 9:8-13.

[18] Hannan A., Asghar S., Naeem T., Ullah M.I., Ahmed I., Aneela S. and Hussain S. (2013). Antibacterial effect of mango (Mangifera indica Linn.) leaf extract against antibiotic sensitive and multi-drug resistant Salmonella typhi. Pak. J. Pharm. Sci. 26:4:715-719.

[19] Kabuki T., Hakajima H., Arai M., Ueda S., Kuwabara Y. and Dosako S. (2000). Characterization of novel antimicrobial compounds from mango (Mangifera indica L) Kernel seeds. Food Chem. 71: 61-66.

[20] Kostakioti M., Hadjifrangiskou M. and Hultgren S.J. (2013). Bacterial biofilms: development, dispersal, and therapeutic strategies in the dawn of the postantibiotic Era. Cold Spring Harb. Perspect. Med. 3:1-23.

[21]Lim K.J.A., Cabajar A.C., Lobarbio C.F.Y., Taboada E.V. and Lacks D.J. (2019). Extraction of bioactive compounds from mango (Mangifera indica L. var. Carabao) seed kernel with ethanol-water binary solvent systems. J. Food Sci. Technol. 56:2536-2544.

[22] Maisuthisakul P. and Gordon M.H. (2009). Antioxidant and tyrosinase inhibitory activity of mango seed kernel by product. Food Chem. 117:332-341.

[23] Manzur A.G.B., Junior V.S.M., Morais-Costa F., Mariano E.G.A., Careli R.T., da Silva L.M.V., Coelho S.G., de Almeida A.C. and Duarte E.R. (2019). Extract of Mangifera indica L. leaves may reduce biofilms of Staphylococcus spp. in stainless steel and teatcup rubbers. Food Sci. Technol. Inter. 26:11-20.

[24] Odonkor S.T. and Addo K.K. (2011). Bacteria resistance to antibiotics: recent trends and challenges. Int. J. Biol. Med. Res. 2:1204-1210.

[25] Pal B.C.T. and Jadeja G.C. (2020). Microwave-assisted extraction for recovery of polyphenolic antioxidants from ripe mango (Mangifera indica L.) peel using lactic acid/sodium acetate deep eutectic mixtures. Food Sci Technol Int. 26:78-92.

[26] Patra J.K. and Baek K.H. (2016). Antibacterial activity and action mechanism of the essential oil from Enteromorpha linza L. against foodborne pathogenic bacteria. Molecules. 21:1-11.

[27] Ramos L., Mellado S., Ramadán S., Bulacio L. and López C. (2006). Empleo de blanco de calcoflúor para el estudio de las especies de Malassezia por microscopia directa. Rev. Argent. Microbiol. 38:4-8. 
The Effect of Seed Extract from Mangifera indica L. on the Growth and Biofilm Formation of Uropathogenic Escherichia coli

[28] Rincón-Mejía C.A., Castaño-Osorio J.C. and Ríos-Vázquez, E. (2012). Actividad biológica de los aceites esenciales de Acmella ciliata (Kunth) Cass. Rev. Cub. Plantas Med. 17:160-171.

[29] Shiau A.L. and Wu C.L. (1998). The inhibitory effect of Staphylococcus epidermidis slime on the phagocitosis of murine peritoneal macrophages is interferon-independent. Microbiol. Inmunol. 42:33-40.

[30] Shibahara A., Yamamoto K., Shinkai K., Nakayama T. and Kajimoto G. (1993). Cis-9, cis-15octadecadienoic acid: a novel fatty acid found in higher plants. Biochim. Biophys. Acta. 1170:245-252.

[31] Thakker M.R., Parikh J.K. and Desai M.A. (2016). Microwaveassisted extraction of essential oil from the leaves of Palmarosa: multi-response optimization and predictive modeling. Indust. Crops Products. 86:311319.

Citation: Flores-Encarnación, M, et.al., The Effect of Seed Extract from Mangifera indica L. on the Growth and Biofilm Formation of Uropathogenic Escherichia coli. International Journal of Research Studies in Biosciences. 2021; 9(2): 15-21. DOI: https://doi.org/10.20431/2349-0365.0902003.

Copyright: () 2021 Authors. This is an open-access article distributed under the terms of the Creative Commons Attribution License, which permits unrestricted use, distribution, and reproduction in any medium, provided the original author and source are credited. 